\title{
Shape-selected bimetallic nanoparticle electrocatalysts: evolution of their atomic-scale structure, chemical composition, and electrochemical reactivity under various chemical environments
}

\author{
Chunhua Cui, ${ }^{a}$ Mahdi Ahmadi, ${ }^{b}$ Farzad Behafarid, ${ }^{b}$ Lin Gan, ${ }^{a}$ \\ Maximilian Neumann, ${ }^{a}$ Marc Heggen, ${ }^{c}$ Beatriz Roldan Cuenya ${ }^{* b}$ \\ and Peter Strasser*a
}

Received 23rd December 2012, Accepted 31st January 2013

DOI: $10.1039 / \mathrm{c} 3 f d 20159 \mathrm{~g}$

Solid surfaces generally respond sensitively to their environment. Gas phase or liquid phase species may adsorb and react with individual surface atoms altering the solid-gas and solid-liquid electronic and chemical properties of the interface. A comprehensive understanding of chemical and electrochemical interfaces with respect to their responses to external stimuli is still missing. The evolution of the structure and composition of shape-selected octahedral PtNi nanoparticles (NPs) in response to chemical (gas-phase) and electrochemical (liquid-phase)

environments was studied, and contrasted to that of pure Pt and spherical PtNi NPs. The NPs were exposed to thermal annealing in hydrogen, oxygen, and vacuum, and the resulting NP surface composition was analyzed using X-ray photoelectron spectroscopy (XPS). In gaseous environments, the presence of $\mathrm{O}_{2}$ during annealing $\left(300^{\circ} \mathrm{C}\right)$ lead to a strong segregation of $\mathrm{Ni}$ species to the NP surface, the formation of $\mathrm{NiO}$, and a Pt-rich NP core, while a similar treatment in $\mathrm{H}_{2}$ lead to a more homogenous Pt-Ni alloy core, and a thinner NiO shell. Further, the initial presence of $\mathrm{NiO}$ species on the as-prepared samples was found to influence the atomic segregation trends upon low temperature annealing $\left(300{ }^{\circ} \mathrm{C}\right)$. This is due to the fact that at this temperature nickel is only partially reduced, and $\mathrm{NiO}$ favors surface segregation. The effect of electrochemical cycling in acid and alkaline electrolytes on the structure and composition of the octahedral PtNi NPs was monitored using image-corrected high resolution transmission electron microscopy (TEM) and high-angle annular dark field scanning TEM (HAADF-STEM). Sample pretreatments in surface active oxygenates, such as oxygen and hydroxide anions, resulted in oxygen-enriched $\mathrm{Ni}$ surfaces (Ni oxides and/or hydroxides). Acid treatments were found to strongly reduce the content of Ni species on the NP surface, via its dissolution in the electrolyte, leading to a Pt-skeleton structure, with a thick Pt shell and a Pt-Ni core. The presence of Ni hydroxides on the NP surface was shown to improve the kinetics of the electrooxidation of $\mathrm{CO}$ and the electrocatalytic hydrogen

\footnotetext{
a Department of Chemistry, Chemical Engineering Division, Technical University, Berlin, Germany.E-mail: pstrasser@tu-berlin.de

${ }^{b}$ Department of Physics, University of Central Florida, Orlando, FL 32816, USA. E-mail: roldan@ucf.edu

${ }^{c}$ Ernst Ruska-Centre for Microscopy and Spectroscopy with Electrons, Forschungszentrum Juelich, Germany
} 
evolution reactions. The affinity to water and the oxophilicity of Ni hydroxides are proposed as likely origin of the observed effects.

Metal alloy particles of nanometer dimensions typically show different surface catalytic reactivity as compared to their bulk alloy form. Since the surface-to-volume ratio increases with decreasing nanoparticle (NP) size, characteristics such as the surface atomic composition and geometrical distribution, alongside with their imperfections (defects), become increasingly relevant at controlling the catalytic behavior of individual metal NPs. This is the origin of size- and shape-dependent reactivities of metal NP catalysts. ${ }^{1-4}$ While the exploration of NP size effects in catalysis has a long history, ${ }^{5-10}$ our understanding of the role of the NP shape in heterogeneous catalysis and electrocatalysis is still in its infancy. ${ }^{11-19} \mathrm{New}$ wet-chemical colloidal synthesis methods have significantly improved our ability to control the size and shape of metal and oxide NPs. ${ }^{18,20-22}$

Other than the particles' geometry, the surface atomic composition of alloy NPs largely affects their catalytic behavior. Although the surface composition is initially determined by molecular processes taking place during the NP synthesis, it is a dynamic parameter. In fact, the surface composition of small NPs is highly sensitive to external stimuli, such as temperature or surface active components in gas- or liquid-phase environments during heterogeneous catalytic and electrocatalytic processes, respectively. In gas-phase catalysis as well as electrochemical catalysis, surface adsorption and reaction can induce surface restructuring ${ }^{22,23}$ or selective surface segregation of an alloy component. ${ }^{24-34}$ Owing to the presence of the segregated component, partially segregated surfaces may display bifunctional catalytic enhancement effects resulting in a new and unexpected catalytic behavior compared to the original surface. Along these lines, the catalytic activity of bimetallic surfaces could be turned on and off by suitable consecutive exposure to segregation-inducing environments.

Several previous experimental and theoretical studies have investigated temperature- ${ }^{35-44}$ and adsorbate-driven ${ }^{45-48}$ segregation process in Pt-Ni systems, including the effect of such segregation in their catalytic reactivity. ${ }^{35,37,49-52}$ In general, segregation phenomena in bimetallic systems can be understood based on the surface energies and atomic radius of the two metals, with the element having a larger atomic radius and a lower surface energy segregating towards the free surface. In the case of platinum and nickel, although platinum has a slightly higher surface energy than $\mathrm{Ni}\left(2.475 \mathrm{~J} \mathrm{~m}^{-2} v s .2 .45 \mathrm{~J} \mathrm{~m}^{-2}\right){ }^{53}$ due to the much larger atomic radius of $\mathrm{Pt}$ $(1.39 \AA)$ as compared to $\mathrm{Ni}(1.24 \AA)$, the segregation of platinum toward the surface is expected, as it was reported for annealing studies in vacuum ${ }^{35-47}$ and in $\mathrm{H}_{2}$ environments. ${ }^{47}$ However, for this material system there is experimental ${ }^{37,38,47,54}$ and theoretical ${ }^{35,40,42,47,50}$ evidence that Pt segregation would only result in the formation of the so called "Pt skin" or "sandwich structure", and not in a phase-separated core-shell structure. The Pt skin refers to a configuration in which the outermost layer is Pt-rich, while the second layer is Ni- rich. Remarkably, although adsorbates could change the segregation properties of the Pt-Ni system, the segregation phenomena appear to be limited to the top-most surface layers. For example, while some density functional theory (DFT) calculations did not predict any segregation due to chemisorbed oxygen, ${ }^{48}$ others showed the formation of a $\mathrm{Ni}$ skin with the outermost layer enriched by $\mathrm{Ni}$ and the second layer by $\mathrm{Pt}^{47}$ In contrast, in cases where oxides might be readily formed, this behavior might be drastically modified, since oxygen might then not only be present at the surface or top-most subsurface region, but also in the bulk of the NPs. In particular, the formation of nickel oxide could contribute to the segregation of Ni to the NP surface, as discussed for various nickel alloys. ${ }^{45}$

In this contribution we investigate the evolution of the structure, composition, and catalytic reactivity of shape-selected octahedral Pt-Ni bimetallic NPs in 
response to various thermal, gas-phase, and electrochemical environments. We follow the changes of the near-surface composition of the PtNi(111) facets after exposure to oxygen and hydrogen gas environments using X-ray photoelectron spectroscopy (XPS) and contrast those to surface compositional transformations during electrochemical potential cycling pretreatments in alkaline and acidic environments. Acidic electrochemical environments dissolve Ni species from the surface leaving behind a Pt enriched interface. Oxygen and hydroxide (alkaline) environments promote the surface segregation of $\mathrm{Ni}$ (II) oxide species, which, owing to their oxophilicity and resulting affinity to water activation, show a significant promotion of the electrochemical $\mathrm{CO}$ oxidation and the electrocatalytic hydrogen evolution. A bifunctional synergetic effect between surface $\mathrm{Pt}$ atoms adjacent to $\mathrm{Ni}$ oxide domains is proposed.

\section{Experimental}

\section{Catalyst synthesis}

Spherical Pt NPs (Pt/C) supported on a high surface area carbon powder. Commercial Vulcan XC $72 \mathrm{R}$ supported Pt NPs with a $15 \%$ loading by weight with a BET value of $151 \mathrm{~m}^{2} \mathrm{~g}^{-1}$ and mean size of about $5 \mathrm{~nm}$ was used as benchmark and standard catalyst ${ }^{55,56,58}$ for $\mathrm{CO}$ electrooxidation and hydrogen evolution. The catalyst was employed as received.

Spherical PtNi NPs (s-PtNi/C) supported on a high surface area carbon powder. To synthesize spherical PtNi NPs, $0.3 \mathrm{mmol}$ of $\mathrm{Ni}(\mathrm{ac})_{2} / 4 \mathrm{H}_{2} \mathrm{O}, 0.4 \mathrm{mmol}$ of 1,2-tetradecandiol, $0.6 \mathrm{~mL}$ of oleic acid, and $0.6 \mathrm{~mL}$ of oleylamine were added into $40 \mathrm{~mL}$ of dioctylether in a three-neck flask. The solution temperature was then increased to $200{ }^{\circ} \mathrm{C}$ in an oil bath during $40 \mathrm{~min}$. Subsequently, $0.3 \mathrm{mmol} \mathrm{Pt}(\mathrm{acac})_{2}$ dissolved in $2 \mathrm{~mL}$ dichlorobenzene was injected into the reaction flask via a syringe. This solution was held at $200{ }^{\circ} \mathrm{C}$ for $1 \mathrm{~h}$ and then cooled down to room temperature (RT). After that, ethanol was added to precipitate the NPs, which were then collected after centrifugation (8000 rpm, $10 \mathrm{~min}$ ). The NPs were further washed in ethanol and then redispersed in hexane. The latter solution was then mixed with Vulcan XC carbon by a ultrasonic treatment. To remove the residual surfactants, the obtained catalysts were heated at $180{ }^{\circ} \mathrm{C}$ in air for $1 \mathrm{~h}$ and further annealed at $400{ }^{\circ} \mathrm{C}$ in $\mathrm{H}_{2}(4 \mathrm{vol} \%$ in $\mathrm{Ar}$ ) for 4 h. ${ }^{57}$

Octahedral PtNi NPs (oct-PtNi/C) supported on a high surface area carbon powder. To synthesize octahedral PtNi NPs, $4 \mathrm{mM} \mathrm{Pt}(\mathrm{acac})_{2}$ and $\left.10 \mathrm{mM} \mathrm{Ni(acac}\right)_{2}$ were mixed together in $100 \mathrm{~mL}$ DMF under ultrasonic treatment. The resulting homogeneous solution was transferred to a glass-lined stainless-steel autoclave and heated from RT to $120{ }^{\circ} \mathrm{C}$ within $10 \mathrm{~min}$. The temperature was held for $42 \mathrm{~h}$. Before washing the particles, the carbon support was added to the solution under ultrasonic treatment. Finally, the oct-PtNi/C was washed with ethanol/water several times.

For the XPS study, three identical PtNi samples containing octahedral NPs were prepared using the same NP solution. The NPs were drop-coated on atomically clean pyrolytic graphite (HOPG) substrates after sonicating the original NP solution for 10 min and subsequently annealed in $\mathrm{O}_{2}, \mathrm{H}_{2}$ and vacuum.

\section{Catalyst film electrode preparation}

A catalyst ink was prepared by mixing the as-prepared catalyst powder in $5 \mathrm{ml}$ of an aqueous and isopropanol solution containing $5 \mathrm{wt} \%$ Nafion and ultrasonicated for $15 \mathrm{~min}$. A $10 \mu \mathrm{l}$ aliquot was dispensed onto the rotating disk electrode (RDE) resulting in a Pt loading of about $7 \mu \mathrm{g} \mathrm{cm}^{-2}$ for s-PtNi/C, $8 \mu \mathrm{g} \mathrm{cm}^{-2}$ for oct-PtNi/C, and $9 \mu \mathrm{g} \mathrm{cm}^{-2}$ for $\mathrm{Pt} / \mathrm{C}$, respectively. Finally, the as-prepared RDE catalyst film was dried at $50{ }^{\circ} \mathrm{C}$ for $15 \mathrm{~min}$. 


\section{Catalyst characterization}

TEM and energy dispersive X-ray spectroscopy (EDX) measurements were performed in a FEI Tecnai G2 20 S-TWIN electron microscope $(200 \mathrm{kV})$ equipped with a $\mathrm{LaB}_{6}$ cathode. High-resolution TEM was performed in an image corrected FEI TITAN 80-300 electron microscope (300 kV). High-resolution STEM and electron energy loss spectroscopy (EELS) experiments were performed in a FEI TITAN 80-300 microscope $(300 \mathrm{kV})$ equipped with a probe corrector and a HAADF detector. 'Z-Contrast' conditions were achieved using a probe semi-angle of 25 mrad and an inner collection angle of the detector of $70 \mathrm{mrad}$. EELS spectra were recorded with a Gatan image filter Tridiem 866ERS system. For the EELS line profile measurements, both Ni- $\mathrm{L}_{2,3}$ and Pt- $\mathrm{M}_{4,5}$ edges spectra were collected across individual NPs with the acquisition time of $2 \mathrm{~s} /$ spectrum. The relative intensities of the Ni- $\mathrm{L}_{2,3}$ and $\mathrm{Pt}-\mathrm{M}_{4,5}$ edges were normalized with respect to their elemental scattering cross sections so that the intensity ratio can be related to the atomic ratio along the electron beam. Inductively coupled plasma (ICP) mass data were obtained by a 715-ES- ICP analysis system (Varian).

The morphology and dispersion of the PtNi NPs supported on HOPG was monitored via atomic force microscopy (AFM) (Digital Instruments, Nanoscope III). On these samples, thermal treatments in different environments were conducted in a high pressure (HP) cell (SPECS GmbH) that allows annealing up to $800^{\circ} \mathrm{C}$ and pressures up to 20 bar. The HP cell was evacuated after each thermal treatment and the samples were directly transferred to the attached ultrahigh vacuum (UHV) system without exposure to air. XPS data were acquired in situ in a UHV chamber equipped with a monochromatic X-ray source (Al-k $\alpha, 1486.6 \mathrm{eV}, 350 \mathrm{~W})$ and an hemispherical electron analyzer (Phoibos 100, SPECS GmbH). For the XPS study, three identical PtNi samples containing octahedral NPs were annealed in 1 bar $\mathrm{O}_{2}, 1$ bar $\mathrm{H}_{2}$, and vacuum environments within the HP cell for $20 \mathrm{~min}$. The temperature ramp was set to $1{ }^{\circ} \mathrm{C} \mathrm{s}^{-1}$. All XPS spectra were measured at RT. The high resolution XPS data were acquired using a pass energy, $\mathrm{E}_{\text {pass }}$, of $18 \mathrm{eV}$. The XPS spectra were analyzed using the CASA XPS software. ${ }^{61}$ All spectra were aligned using the C-1s peak from the graphite support at $284.3 \mathrm{eV}$ as reference. The $\mathrm{Ni} / \mathrm{Pt}$ atomic ratios were obtained from the area under the $\mathrm{Ni}-2 \mathrm{p}$ and $\mathrm{Pt}-4 \mathrm{f}$ peaks after normalization by the corresponding atomic sensitivity factors of 26.08 and 14.99 , respectively. ${ }^{61}$

\section{Electrochemical pretreatments}

All electrochemical measurements were carried out in a conventional three electrode cell, employing a $\mathrm{Pt}$ gauze as counter electrode and a commercial reversible hydrogen electrode (RHE) ${ }^{59,60}$ All potentials here are referenced to this reference electrode. Electrochemical catalyst pretreatments are illustrated in Fig. 1. Pt/C, s-PtNi/C and oct-PtNi/C catalysts were cycled between 0.06 and $0.6 \mathrm{~V}_{\mathrm{RHE}}$ at $100 \mathrm{mV} \mathrm{s}^{-1}$ in deaereated $0.1 \mathrm{M} \mathrm{KOH}$ alkaline or $0.1 \mathrm{M} \mathrm{HClO}_{4}$ acidic solutions. Catalysts that underwent 1 and 20 cycles in alkaline are denoted as "1-alkaline" and "20-alkaline", respectively. s-PtNi/C and oct-PtNi/C catalysts that were cycled 100 times in $0.1 \mathrm{M} \mathrm{HClO}_{4}$ under otherwise identical conditions were denoted "100-acid", see Fig. 1.

\section{CO electrooxidation measurements}

The electrochemically pretreated $\mathrm{Pt} / \mathrm{C}, \mathrm{s}-\mathrm{PtNi} / \mathrm{C}$ and oct-PtNi/C catalysts were tested for their electrooxidation (stripping) of adsorbed $\mathrm{CO}$ at saturation coverage. The CO stripping of "1-alkaline" and " 20 -alkaline" was performed in $0.1 \mathrm{M} \mathrm{KOH}$ alkaline solutions only, while the "100- acid" acid-pretreated samples were measured in both alkaline $0.1 \mathrm{M} \mathrm{KOH}$ and $0.1 \mathrm{M} \mathrm{HClO}_{4}$ acid solutions, Fig. 1. $\mathrm{CO}$ adsorption was carried out at a constant electrode potential of $+0.05 \mathrm{~V}$ versus $\mathrm{RHE}$ by flowing $\mathrm{CO}$ gas through the electrolyte for $15 \mathrm{~min}$. Then, the gas was switched to $\mathrm{N}_{2}$ for 


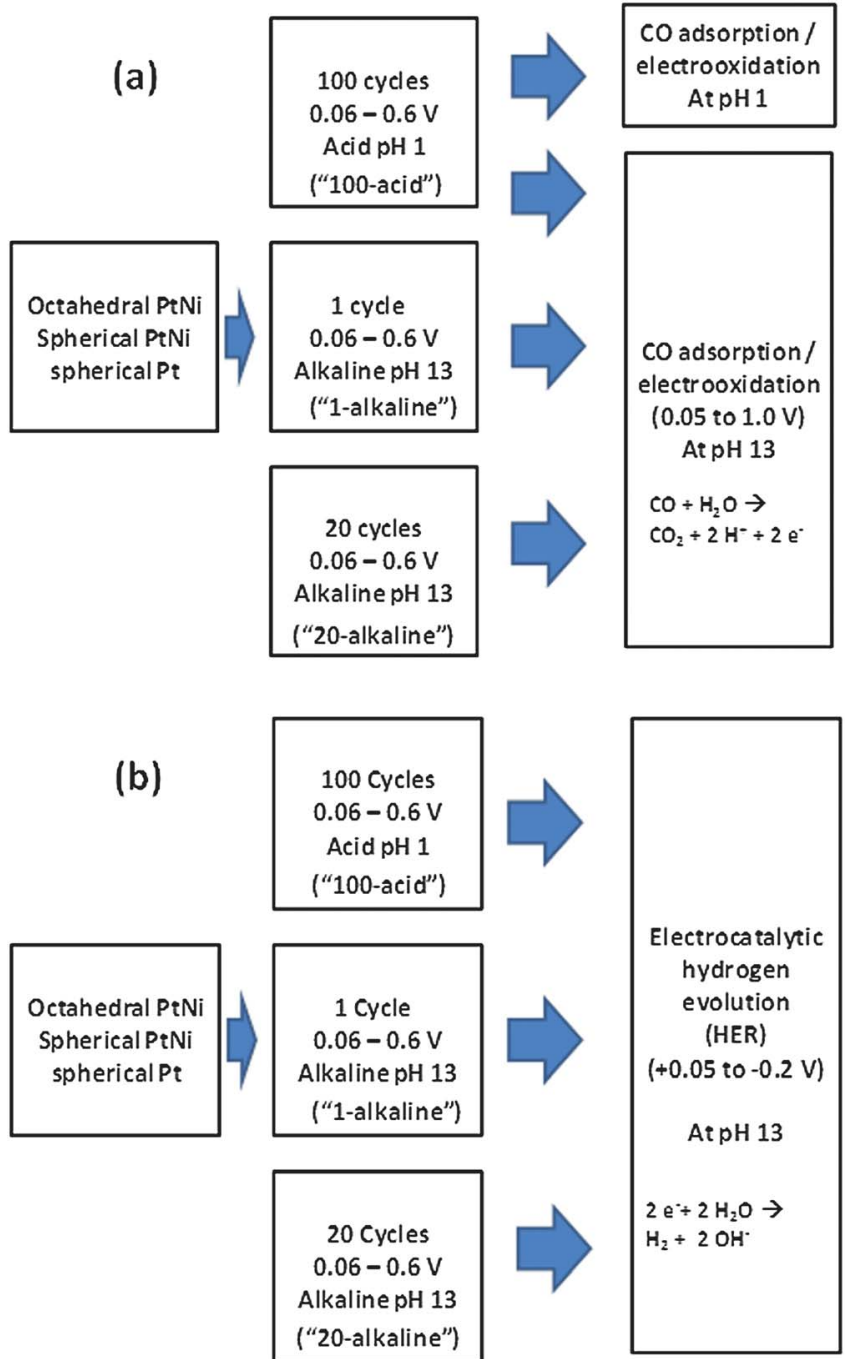

Fig. 1 (a) Nanoparticle catalyst pretreatments and electrocatalytic $\mathrm{CO}$ oxidation in acid and alkaline conditions, (b) pretreatments (acid and alkaline) and electrocatalytic hydrogen evolution reaction testing (alkaline) of Pt and PtNi NPs.

15 min to remove excess non-adsorbed $\mathrm{CO}$ gas in the electrolyte solution while keeping the potential constant. After that, the potential was scanned from +0.05 to $+1.0 \mathrm{~V}$ versus $\mathrm{RHE}$ to record the $\mathrm{CO}$ stripping. One additional potential cycle was conducted in order to record the $\mathrm{H}_{\text {upd }}$ charge value as well as the electrochemical response of the surface at $50 \mathrm{mV} \mathrm{s}^{-1}$.

\section{Hydrogen evolution reaction measurements}

After the electrochemical pretreatments, the RDE was transferred into an electrochemical cell containing a $\mathrm{H}_{2}$-saturated $0.1 \mathrm{M} \mathrm{KOH}(\mathrm{pH} 13)$ solution. In each experiment, the electrode was immersed in the solution at $+0.05 \mathrm{~V}$. Then, the HER polarization curves were recorded between $-0.2 \mathrm{~V}$ and $+0.05 \mathrm{~V}$ versus $\mathrm{RHE}$ at a scan rate of $1 \mathrm{mV} \mathrm{s}^{-1}$ as shown in Fig. 1. The HER activities were normalized to 
the catalytically active real surface area (ECSA), which was evaluated by CO stripping.

\section{Results and discussion}

\section{Structural and morphological characterization (TEM, AFM)}

As described in the experimental section, octahedral PtNi bimetallic NPs with a bulk $\mathrm{Pt}$ : Ni ratio of $1: 1$ were prepared using wet-chemical methods (solvothermal process at elevated pressures), ${ }^{62}$ with DMF serving as solvent and reducing agent. ${ }^{63,64}$ The spherical NPs were prepared using an ambient pressure hot-injection technique ${ }^{65}$ at $200{ }^{\circ} \mathrm{C}$ involving a high-boiling point solvent, surfactants and reducing agents as separate components. ${ }^{66}$

Fig. 2 shows TEM and HAADF STEM micrographs of as-prepared unsupported octahedral PtNi (oct-PtNi) NPs. The particles exhibited a narrow size distribution with a mean diameter of about $9 \mathrm{~nm}$. EELS data ${ }^{64}$ exhibited the composition distribution and STEM image in Fig. 2d showed the octahedral structure in the PtNi nanoparticles. Fig. 3 shows TEM and HAADF STEM images of the unsupported and carbon-supported spherical PtNi (s-PtNi) NPs. Particle sizes were narrowly distributed around a mean of about $6 \mathrm{~nm}$. X-Ray diffraction patterns (not shown) and EELS intensity line scans for Pt and Ni, Fig. 3(d), for selected individual NPs showed that the catalyst consisted of a single face-centered-cubic bimetallic alloy phase with a fairly homogeneous distribution of $\mathrm{Pt}$ and $\mathrm{Ni}$ atoms at the atomic scale. Pt to Ni intensity ratios across an individual NP are close to 1 , which is consistent with the PtNi bulk composition. The particle center appears to be slightly enriched in $\mathrm{Ni}$, indicating the formation of Ni-rich alloy seeds during the reduction process.

Fig. 4 shows an AFM image of the as prepared $\mathrm{Pt}_{50} \mathrm{Ni}_{50} / \mathrm{HOPG}$ sample. The average NP height obtained is $3.7 \pm 0.8 \mathrm{~nm}$. The atomic steps of the HOPG surface can be observed, and NP decoration of step edges is evident.
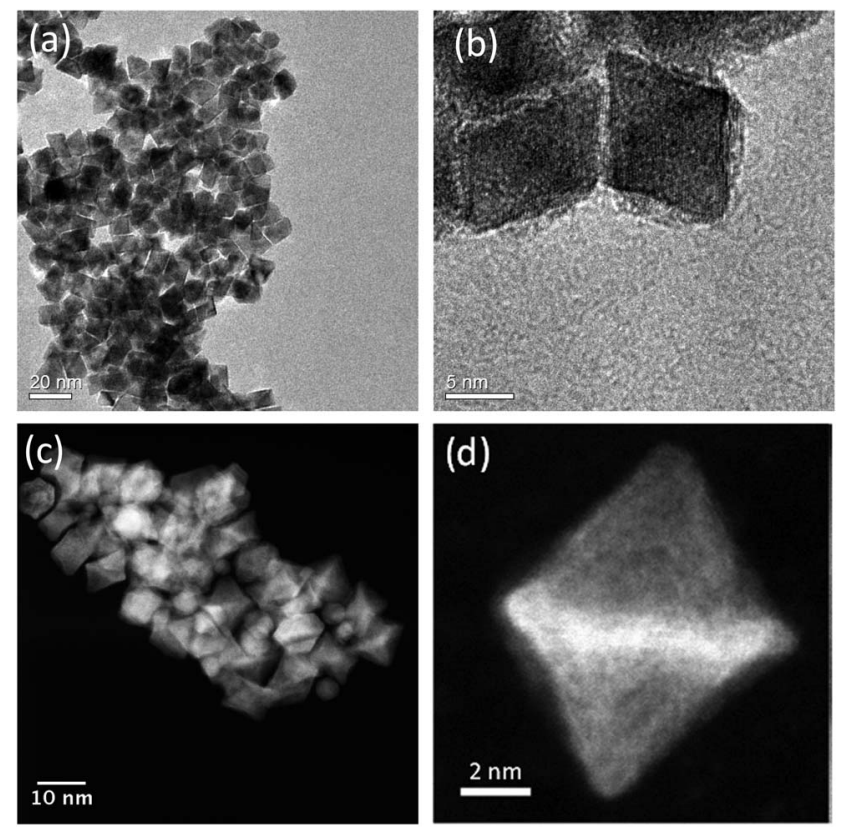

Fig. 2 TEM images of as-prepared octahedral PtNi(oct-PtNi); (a) unsupported oct-PtNi; (b) a zoomed-in region of (a); (c) HAADF STEM image of oct-PtNi NPs; (d) HAADF STEM image of a single octahedral PtNi NP. 

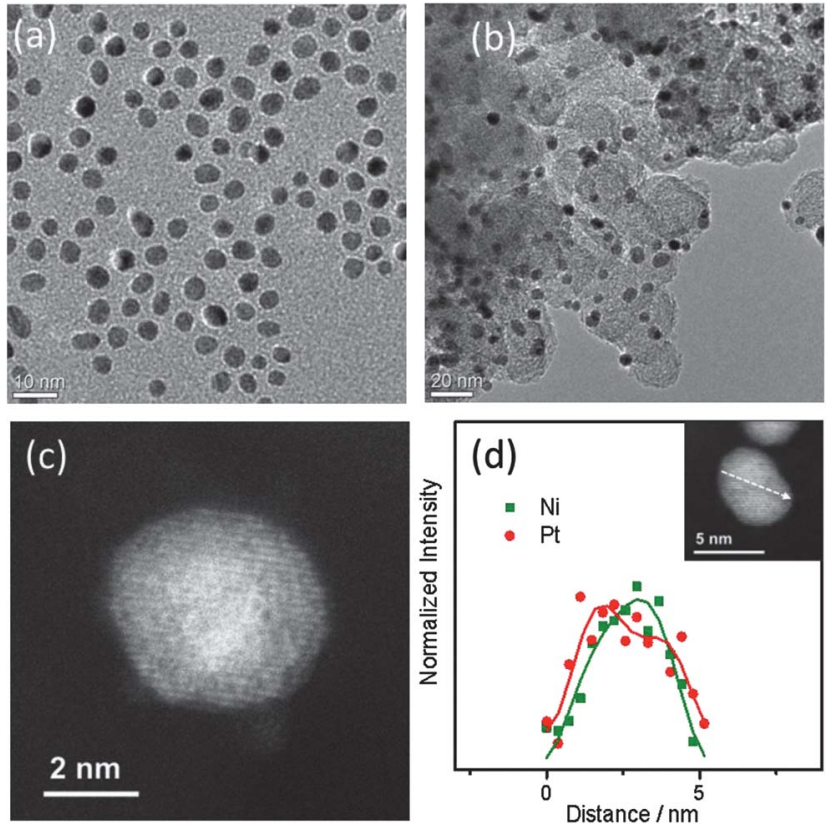

Fig. 3 TEM images of as-prepared spherical PtNi(s-PtNi) NPs: (a) unsupported s-PtNi, (b) carbon-supported s-PtNi, (c) HAADF-TEM image of an individual PtNi NP, (d) STEM EELS line scan (along the arrow in the inset) of a single PtNi NP showing the spatial distribution of $\mathrm{Ni}$ and $\mathrm{Pt}$.

\section{Evolution of surface composition under chemically reactive gas and liquid environments}

Gas-phase pretreatments. Fig. 5 shows XPS data from the Pt-4f and Ni-2p core level regions of one of the as-prepared samples together with spectra acquired on identical samples after in situ thermal treatments at $300{ }^{\circ} \mathrm{C}$ for $40 \mathrm{~min}$ in different environments, namely in $\mathrm{UHV}$, in 1 bar of $\mathrm{O}_{2}$, and in 1 bar of $\mathrm{H}_{2}$. Higher annealing

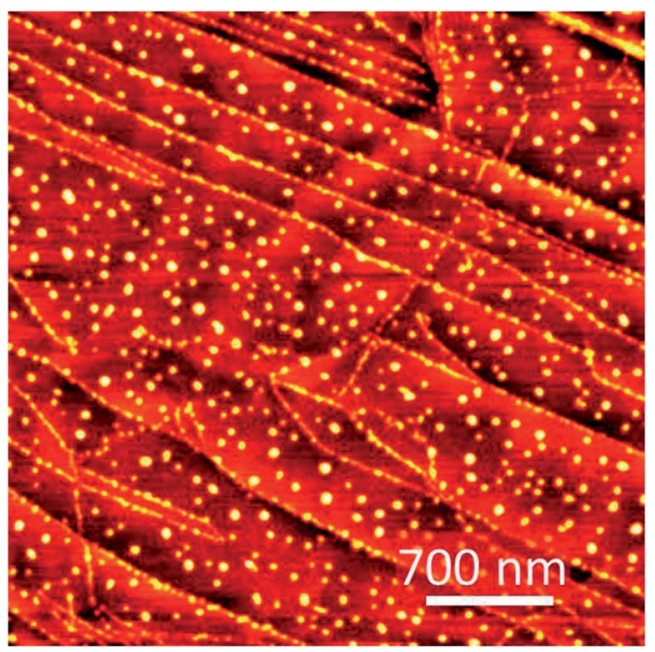

Fig. 4 AFM image of an as-prepared PtNi NP sample acquired at RT in air. 
temperatures were avoided due to concerns regarding possible NP shape transformations. However, Monte Carlo simulations of PtNi NPs annealed in vacuum at $330{ }^{\circ} \mathrm{C}$ demonstrated no drastic change in the shape of octahedral NPs. ${ }^{42}$

The Pt-4f spectra in Fig. 5(a) were fitted with three doublets $\left(4 \mathrm{f}_{7 / 2}\right.$ and $\left.4 \mathrm{f}_{5 / 2}\right)$ corresponding to $\mathrm{Pt}^{0}, \mathrm{Pt}^{2+}$ and $\mathrm{Pt}^{4+}$ with binding energies in agreement with those previously reported. ${ }^{67}$ The Ni-2p core level region was fitted with two doublets corresponding to $\mathrm{Ni}$ and $\mathrm{Ni}^{2+}\left(2 \mathrm{p}_{3 / 2}\right.$ and $\left.2 \mathrm{p}_{1 / 2}\right)$ and a third one accounting for satellite peaks. ${ }^{6,69}$

The content of the different $\mathrm{Pt}$ and $\mathrm{Ni}$ species as well as the $\mathrm{Ni} / \mathrm{Pt}$ ratio after the different treatments is shown in Fig. 6. The as prepared samples contain metallic and oxidic $\mathrm{Pt}$ species $\left(\mathrm{PtO}\right.$ and $\left.\mathrm{PtO}_{2}\right)$, while the $\mathrm{Ni}$ is mainly in the form of $\mathrm{NiO}$. Upon annealing in vacuum or hydrogen, the partial reduction of both $\mathrm{PtOx}$ and $\mathrm{NiOx}$ species is evident from the increase in the content of the respective metallic components, Fig. 5 and 6 . While $\mathrm{Pt}$ is completely reduced in $\mathrm{H}_{2}$ at $300^{\circ} \mathrm{C}$, a relatively large $\mathrm{NiO}$ content is still observed, as expected due to the higher affinity of nickel for oxygen as compared to platinum. Nevertheless, the most significant effect was observed upon annealing in oxygen, with not only the total oxidation of $\mathrm{Ni}$, but also a drastic increase in the intensity of the Ni signal. On the other hand, for the Pt component, only an increase in the $\mathrm{Pt}^{4+}$ content is detected, with metallic Pt species being still present. These results suggest that under those conditions, a Pt-rich NP core might be protected by a NiO shell.

Fig. 6(c) shows the $\mathrm{Ni} / \mathrm{Pt}$ ratio for the as prepared sample as well as that obtained after annealing in different environments. The $\mathrm{Ni}: \mathrm{Pt}$ ratio increases in all cases after the thermal treatments, with the $(\mathrm{Ni}: \mathrm{Pt})_{\mathrm{O}_{2}}>(\mathrm{Ni}: \mathrm{Pt})_{\text {Vacuum }}>(\mathrm{Ni}: \mathrm{Pt})_{\mathrm{H}_{2}}$. As it was mentioned in the introduction, the segregation of $\mathrm{Pt}$ induced by annealing in vacuum or $\mathrm{H}_{2}$ environments would be hard to detect using XPS since it only affects the composition of the outermost layers of the NPs. The increase observed here is most likely due to initial presence of the oxide. To the best of our knowledge, there is no theoretical study predicting the segregation behavior of $\mathrm{Pt}$ and $\mathrm{Ni}$ in the presence of such oxide species. However, our XPS measurements revealed that as long as the $\mathrm{Ni}$ oxide is present in the NPs, a shell of $\mathrm{NiO}$ and a core of $\mathrm{Pt}$ will form upon heating, regardless of the chemical environment. Interestingly, the final content of $\mathrm{Ni}$ at the NP surface appears to be proportional to the extent of the oxidation of the Ni component after a given treatment. This can be seen by comparing the $\mathrm{Ni}^{2+}$ contributions in Fig. 6(b) and the Ni/Pt ratios in Fig. 6(c) after the different

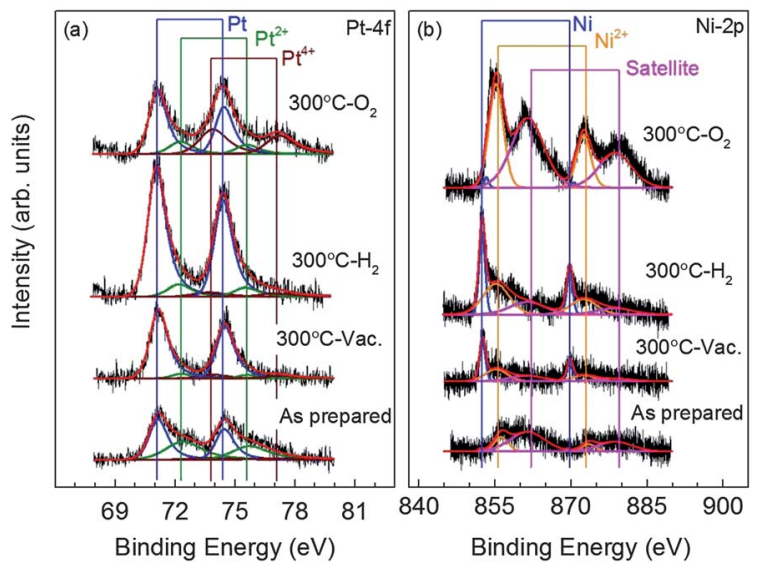

Fig. 5 XPS spectra from the (a) Pt-4f and (b) Ni-2p core level regions of PtNi NPs supported on HOPG acquired at RT before (as prepared) and after annealing in vacuum and in 1 bar of $\mathrm{O}_{2}$ and $\mathrm{H}_{2}$ at $300{ }^{\circ} \mathrm{C}$ for $20 \mathrm{~min}$. 

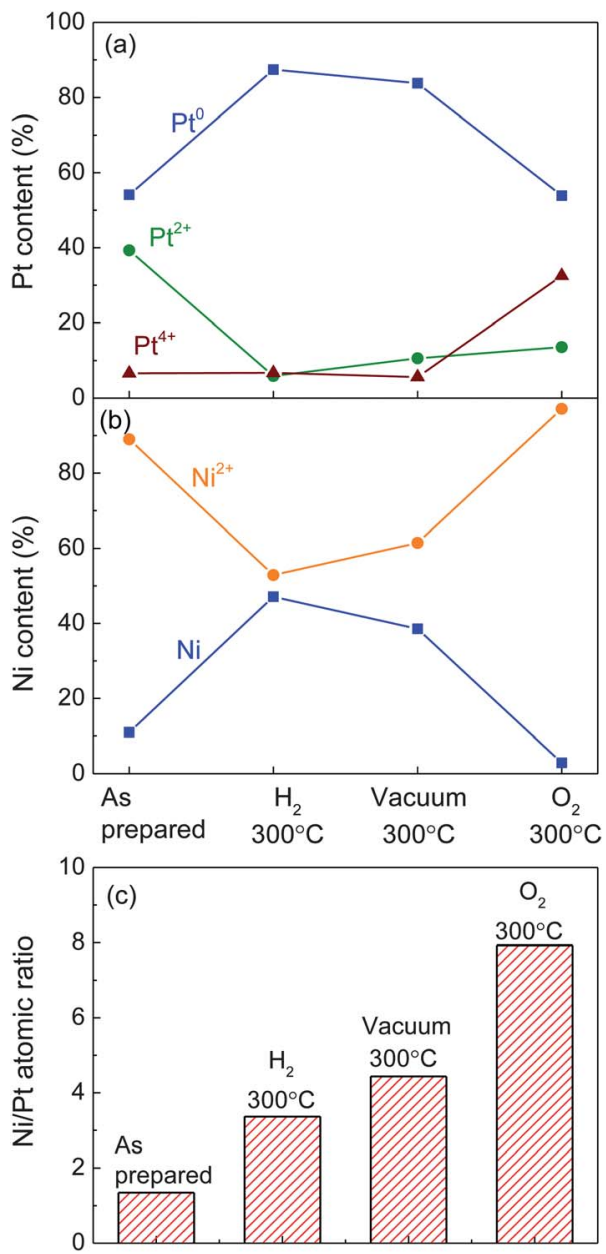

Fig. 6 Relative content of (a) Pt and (b) Ni species extracted from the XPS measurements in Fig. 5. (c) Ni/Pt atomic ratio obtained for the as prepared sample and analogous fresh samples after the indicated sample treatments.

treatments. For both parameters, the lowest content is observed after the thermal treatment in $\mathrm{H}_{2}$, followed by the vacuum annealing, and the maximum after $\mathrm{O}_{2}$ exposure at the same temperature $\left(300^{\circ} \mathrm{C}\right)$.

As was mentioned in the introduction, the formation of nickel oxide could contribute to the segregation of Ni to the NP surface. By reducing the NiO via annealing in vacuum or hydrogen environments, Ni can diffuse back into the Pt core and form a uniform Pt-Ni alloy. The onset temperature for Ni diffusion into $\mathrm{Pt}(111)$ single crystals and alloy formation has been experimentally reported to vary between $180{ }^{\circ} \mathrm{C}-380{ }^{\circ} \mathrm{C}$, depending on the Ni coverage $(0.8-3 \mathrm{ML}) .{ }^{44}$ Fig. 7 displays a model of the distribution of $\mathrm{Pt}, \mathrm{Ni}, \mathrm{PtOx}$ and NiOx species on the octahedral NPs after the different in situ thermal treatments.

Electrochemical potential cycling pretreatments. Having explored the surface redox and segregation phenomena of oct-PtNi NPs in gas-phase chemical environments, we performed a similar study in electrochemical environments and tested the effect of the changes in the surface structure and composition on the catalytic reactivity. 
To achieve that, we subjected samples containing carbon-supported octahedral (oct$\mathrm{PtNi}$ ) and spherical (s-PtNi) alloy NPs to three different potential cycling protocols, two in alkaline $(0.1 \mathrm{~m} \mathrm{KOH})$ and one in acidic $\left(0.1 \mathrm{~m} \mathrm{HClO}_{4}\right)$ electrochemical environments. We chose a potential range from +0.05 to $+0.6 \mathrm{~V} / \mathrm{RHE}$ for each cycle such that the evolution of the surface composition would not be influenced by the formation of $\mathrm{Pt}$ oxides, while $\mathrm{Ni}$ and $\mathrm{NiO}$ surface species could form, segregate, or dissolve. The cycling pretreatments included: i) a single cycle in an alkaline solution representing a standard measurement close to the pristine state of the catalyst surface (1-alkaline), ii) 20 potential cycles in an alkaline solution, because this treatment yielded a stable cyclic voltammogram (not shown) and showed a maximum in catalytic HER performance (see below), and iii) 100 potential cycles in an acidic electrolyte, after which the cyclic voltammogram was stable with time and resembles in shape that of a pure $\mathrm{Pt}$ surface, indicating the complete loss of $\mathrm{Ni}$ or $\mathrm{NiO}$ from the top layer.

The effect of the pretreatments in the three electrochemical environments on the morphology and chemical composition of the oct-PtNi NPs is displayed in Fig. 8 and 9, where Z-contrast TEM scans along the $<110>$ and $<100>$ directions are shown.

In these images, the Z-contrast scales with nearly the power of 2 of the atomic number of the elements along the scanned electron beam direction, and hence carries compositional information along with thickness information. Fig. 8(a) and 8(d) represent the near-pristine state of the octahedral NPs.

Fig. 8(b) and 8(e) evidence that 20 cycles in the alkaline solution did not have a significant effect on the morphology or Z-contrast, except perhaps a slightly darkened contrast near the bottom vertex of the image in Fig. 8(b) (see arrow). Darkened regions can be explained by reduced specimen thickness or enrichment in the lighter element at comparable thickness. Since the alkaline environment precludes the dissolution of either $\mathrm{Pt}$ or $\mathrm{Ni}$, an enrichment in $\mathrm{Ni}$ or $\mathrm{Ni}$ oxides is a likely explanation. Fig. 8(c) and 8(f) show a clearly increased Z-contrast between the bright central octahedral edges and the opposite facets and vertex regions. Since acidic conditions are known to dissolve $\mathrm{Ni}$ and $\mathrm{Ni}$ hydroxide surface species, a thinning of the specimen by selective metal dissolution appears as a likely explanation for the changes in the Z-contrast. Also, along the $<100>$ direction in Fig. 8(f), the enhanced Z-contrast between the central octahedral frame and the (111) facet region is consistent with a reduced thickness of the facet region. To support the latter conclusion we performed additional STEM and high resolution TEM studies on acid-leached octPtNi. The high resolution TEM image in Fig. 9(b) confirms that the acid-cycled octahedra suffered from selective surface dissolution of $\mathrm{Ni}$ and $\mathrm{Ni}$ hydroxide species near the facet centers, resulting in a concave facet morphology. Fig. 9(c) illustrates schematically the morphology of the resulting Pt-rich concave octahedra NP formed during the treatment of oct-PtNi in acidic environments.

In order to gain further insight into the surface and near-surface composition of the electrochemically-treated samples, we have measured the octahedral and
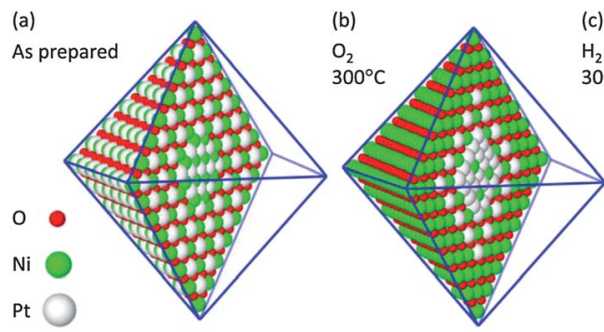

(c)

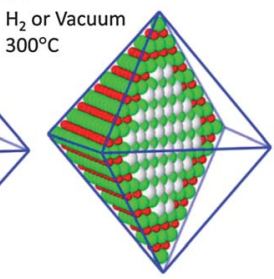

Fig. 7 Model describing the segregation phenomena observed via XPS for the octahedral PtNi NPs after annealing at $300{ }^{\circ} \mathrm{C}$ in different gaseous environments. 

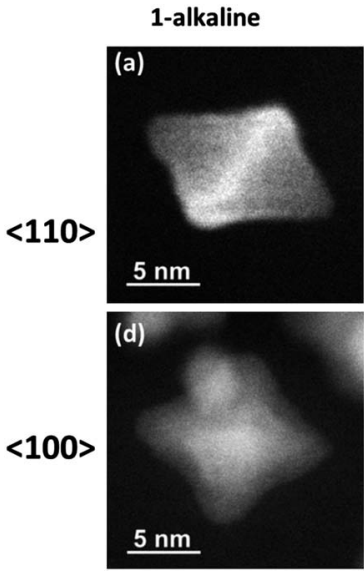

20-alkaline
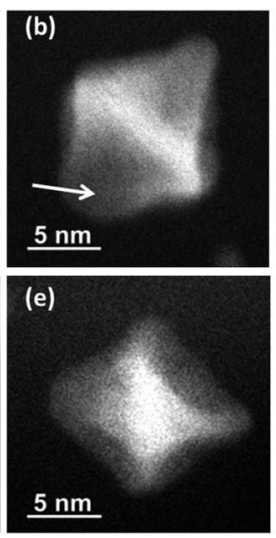

100-acid
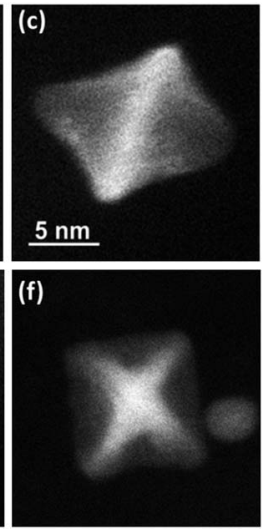

Fig. 8 (a) HAADF STEM images along the $(\mathrm{a}-\mathrm{c})<110>$ and $(\mathrm{d}-\mathrm{f})<100>$ zone axes of the three differently pretreated octahedral PtNi NPs (oct-PtNi/C): (a,d) "1-alkaline", (b,e) "20alkaline", (c,f) "100-acid".
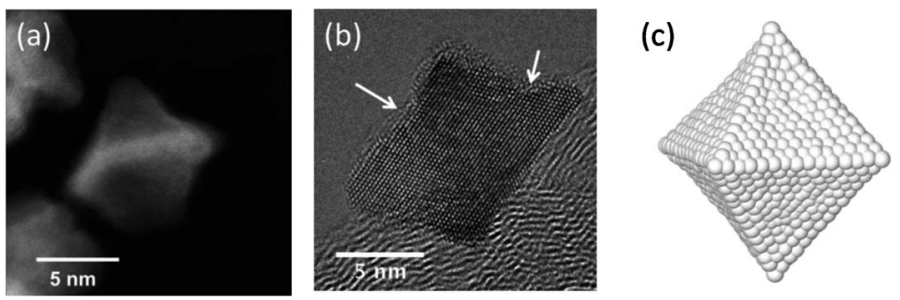

Fig. 9 (a) HAADF STEM image, (b) high resolution TEM image of an acid-leached concave octahedron, and (c) schematic concave octahedral structure of oct-PtNi/C after potential cycling in an acidic $0.1 \mathrm{~m} \mathrm{HClO}_{4}$ electrolyte. The model NP displays a Pt-rich structure after $\mathrm{Ni} / \mathrm{Ni}(\mathrm{OH})_{2}$ dissolution.

spherical PtNi NPs supported on flat adhesive graphite tabs after 1 and 20 cycles in the alkaline solution, and after 100 cycles in the acid solution via ex situ XPS. Fig. 10 shows Pt-4f and Ni-2p XPS data of oct-PtNi and s-PtNi NPs after the different electrochemical treatments. After one cycle from $0.05 \mathrm{~V}$ to $0.6 \mathrm{~V}$ and back to $0.05 \mathrm{~V}$ in an alkaline electrolyte, platinum is reduced to the metallic state, while Ni is partially oxidized in the s-PtNi NPs and completely oxidized in the oct-PtNi NPs, Fig. 11(a),(b). The initial Ni : Pt ratios in the electrochemical environment were significantly higher than those under UHV gas-phase conditions, suggesting the formation of a thick Ni-rich surface layer in the liquid environment. Additional potential cycling in the alkaline solution (20 and 100 cycles) lead to a slight decrease in the Ni : Pt ratio, signalling a Pt-richer surface/near surface NP region, Fig. 11(c). According to their Pourbaix behavior, Ni hydroxides cannot chemically dissolve under $\mathrm{pH}=13$ conditions. Thus, the decrease $\mathrm{Ni} / \mathrm{Pt}$ in the ratio observed either originated from an electrochemical surface segregation of Pt species, or else, from a partial surface $\mathrm{Ni}$ hydroxides reduction at the low electrode potential limit $(0.05 \mathrm{~V})$ and subsequent $\mathrm{Ni}$ inward diffusion and $\mathrm{Pt}-\mathrm{Ni}$ alloy formation inside the NP core. The appearance of a small $\mathrm{Pt}^{2+}$ component in the XPS data of the octahedral NPs might correlate with the facile electrochemical oxidation of low-coordinated surface Pt atoms near the corners and edges of the octahedral NP surface. It should also be noted that these samples were all measured after transfer in air to the UHV XPS system, and therefore, it cannot be ruled out that a fraction of 


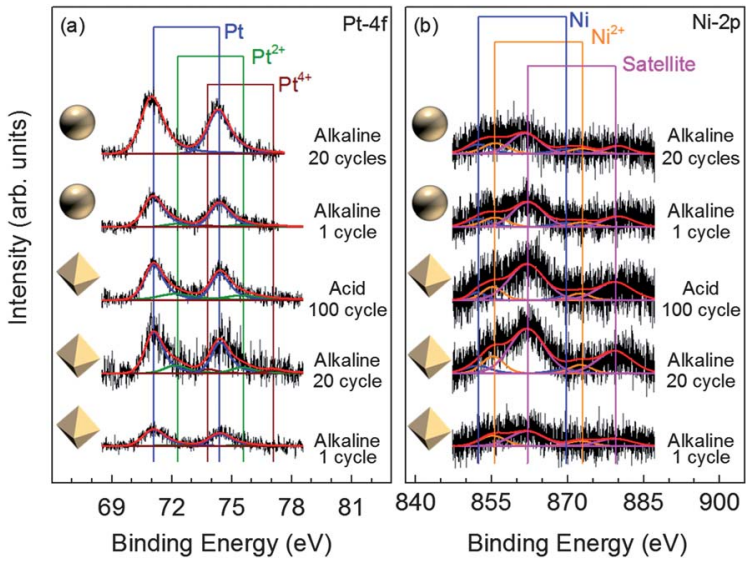

Fig. 10 XPS spectra from the (a) Pt-4f and (b) Ni-2p core level regions of octahedral and spherical PtNi NPs supported on a high surface area carbon black acquired after different voltammetry cycles in alkaline and acid solutions.

the oxidic Pt and Ni species observed at the NP surface could originate from the air exposure. Nevertheless, as mentioned before, PtOx species were not observed on the 1-alkaline oct-PtNi NP sample. Similar observations were made for the spherical PtNi NPs after identical treatments in the alkaline solution, Fig. 11. However, a larger decrease in the $\mathrm{Ni}$ content at the NP surface was obtained for s-PtNi as compared to oct-PtNi after the first 20 cycles in the alkaline solution. Whether that is exclusively attributable to a shape effect or whether a size effect is co-involved remains speculative given our data. Subsurface Ni atoms may prefer to move away from the surface and alloy within the NP core during cycling; or else, Pt may be more mobile due to its lower average surface coordination and hence preferably surface segregate. Also, in contrast to the octahedral NPs, the dominant Pt component in the spherical NPs remained metallic Pt.

After 20 and 100 voltammetry cycles in the acidic solution, a strong decrease in the $\mathrm{Ni} / \mathrm{Pt}$ ratio is observed, Fig. 11(c). In light of the TEM measurements, such observation can be attributed to the selective surface Ni dissolution in the acid electrolytes. Interestingly, in this case platinum appears to be partially oxidized $\left(\mathrm{Pt}^{2+}\right)$, while nickel is partially reduced, Fig. 11(a),(b). Here, the partial oxidation of Pt might be again related to the low Pt coordination or due to the removal of the protective $\mathrm{Ni}$ shell into the electrolyte during the acidic potential cycling.

\section{Electrocatalytic activity}

CO oxidation. To study the impact of the electrochemical pretreatments and resulting surface structure of the oct-PtNi/C and s-PtNi/C NPs on their electrocatalytic properties, the pretreated " 20 -alkaline" and " 100 -acid" oct-PtNi/C samples were used for the electrocatalytic oxidation of a pre-adsorbed monolayer of $\mathrm{CO}$ during a cyclic voltammetric sweep. Conceptually, this electrochemical reactivity measurement is equivalent to a temperature ramp during a gas-phase catalytic temperature-programmed-oxidation (TPO) experiment. First, a study of the oxidative CO stripping of the " 100 -acid" oct-PtNi/C and s-PtNi/C samples was performed in acid and alkaline electrolytes, and compared to a pure Pt/C NP catalyst. The black traces marked "1." in Fig. 12(a),(b), and (c) show the first cyclic voltammograms $(\mathrm{CVs})$ in acid. Between $0.05 \mathrm{~V}$ and $0.6 \mathrm{~V}$ all initial anodic voltammograms remained flat at vanishing current densities, consistent with a fully $\mathrm{CO}$-covered, and hence poisoned and inactive $\mathrm{Pt}$ surface. $\mathrm{CO}$ electrooxidation on $\mathrm{Pt}$ started with a small 

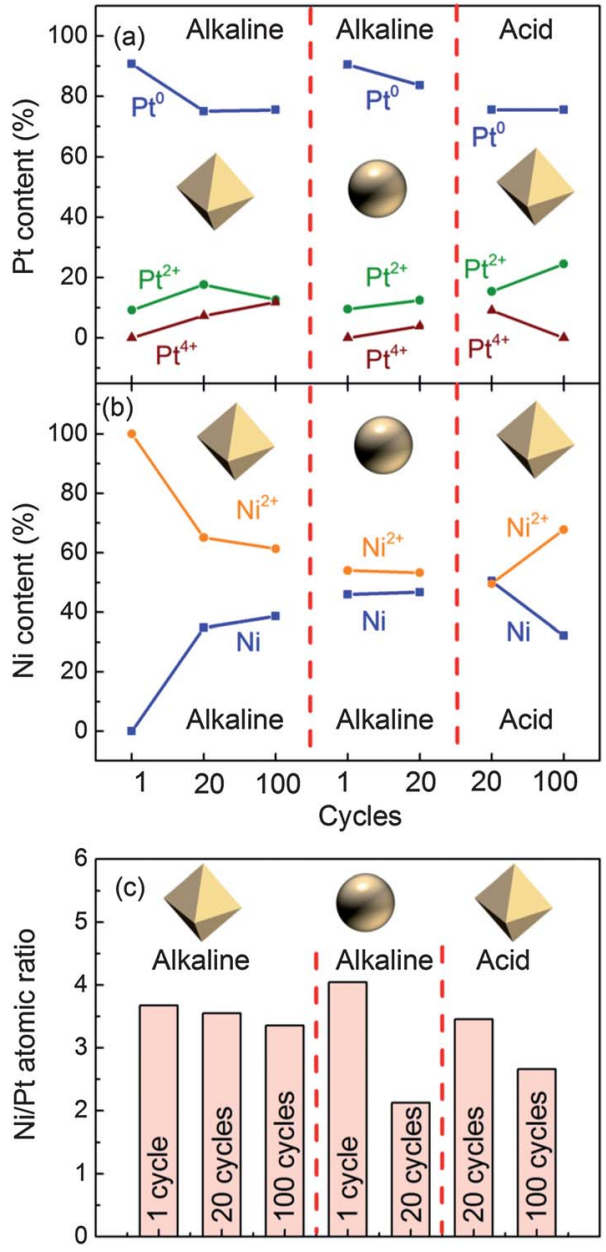

Fig. 11 Relative content of (a) Pt and (b) Ni species extracted from the XPS measurements in Fig. 10. (c) Ni/Pt atomic ratio obtained after a different number of voltammetry cycles in alkaline and acid solutions.

pre-peak feature around $0.72 \mathrm{~V}$, followed by the main peak around $0.85 \mathrm{~V}$, Fig. 12(a). The shape of the cyclic voltammogram is fully consistent with previous CO studies of Pt NPs of comparable size. ${ }^{70,71}$ In contrast, the "100-acid" oct-PtNi/ $\mathrm{C}$ and s-PtNi/C samples showed a $130 \mathrm{mV}$ cathodic shift of the major $\mathrm{CO}$ oxidation peak. Following earlier arguments this can be attributed to a weaker interaction of surface Pt atoms with adsorbed CO. Alternatively, low-coordinated Pt atoms formed during the acidic leaching process could serve as active adsorption sites for water activation, resulting in adsorbed $\mathrm{OH}$ species that remove $\mathrm{CO}$. The small differences between the acid-treated octahedral and the spherical NP catalysts suggest a fairly limited impact of the NP shape on the CO stripping process. Instead, the electrocatalytic properties appear to be controlled by the surface and nearsurface composition.

In alkaline environments the voltammetric $\mathrm{CO}$ oxidation peaks showed a significant cathodic potential shift. The Pt/C NPs showed a CO stripping onset potential of about $0.6 \mathrm{~V}$, Fig. 12(a), followed by a gradual current increase peaking at $0.7 \mathrm{~V}$ (marked as "Pt"). The potential shift can be explained by the presence of reactive adsorbed hydroxide anions, which cause $\mathrm{CO}$ oxidation at lower electrode potentials. 

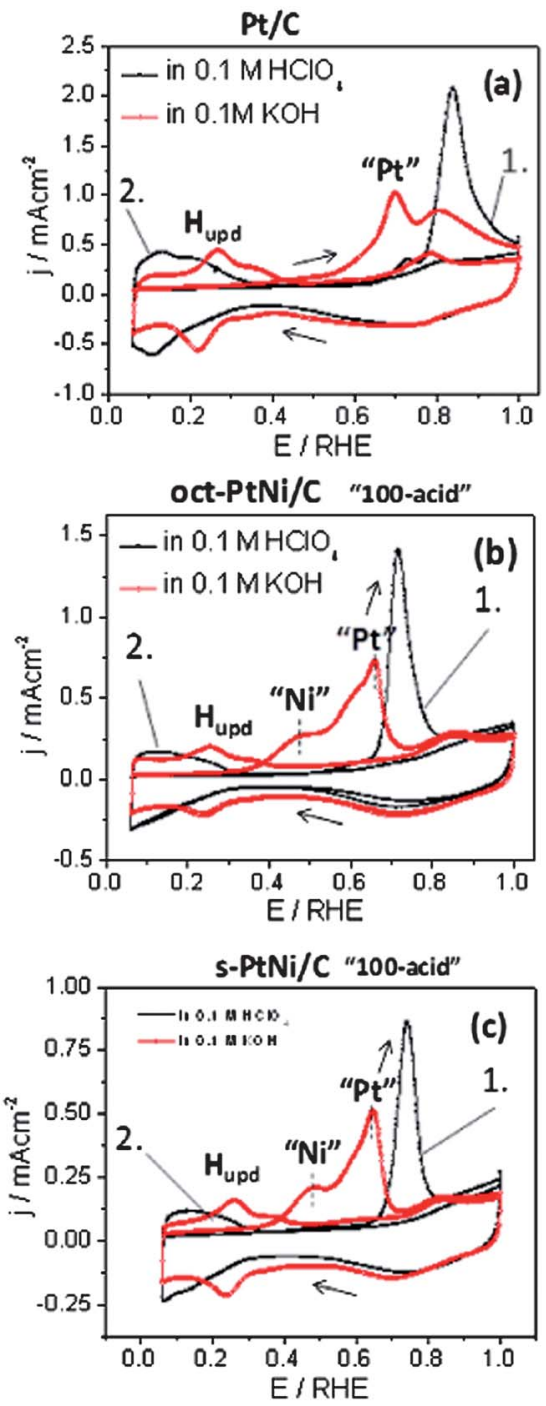

Fig. 12 Comparison of the electrocatalytic $\mathrm{CO}$ oxidation in alkaline (red) and acid solution (black) of: (a) Pt/C, (b) "100-acid" pretreated oct-PtNi/C, and (c) "100-acid" pretreated s$\mathrm{PtNi} / \mathrm{C}$. Scan numbers are shown. Arrows indicate scan directions. "Pt" and "Ni" mark major $\mathrm{CO}$ oxidation peaks.

A severe cathodic shift in the $\mathrm{CO}$ oxidation onset potential was observed for the PtNi/C NPs. Both, octahedral and spherical "100-acid" PtNi NPs exhibited a new $\mathrm{CO}$ oxidation peak at around $0.5 \mathrm{~V}$ (marked "Ni"). Being shape-independent and absent for the pure Pt NPs, we conclude that this feature is associated with the presence of $\mathrm{Ni}$ or Ni-hydroxides in or near the catalyst surface. It is reasonable to assume that the Ni species effectively catalyze the activation of water molecules and serve as supply for active oxygenates to oxidize surface CO.

The second voltammetric cycle of the NPs in acid and alkaline environments (marked "2" in Fig. 12) showed the characteristic peak features associated with the underpotential deposition and removal of atomic hydrogen $\left(\mathrm{H}_{\text {upd }}\right)$ in acid and alkaline electrolytes. 
A separate comparative study of the $\mathrm{CO}$ oxidation behavior of alkaline-pretreated octahedral and spherical NPs ("1-alkaline" and "20-alkaline" NPs) and acid-pretreated NPs ("100-acid") was carried out and the results are displayed in Fig. 13. The CO stripping curve of both octahedral and spherical "1-alkaline" NPs showed an unexpectedly intense CO removal peak (marked "Ni") in Fig. 13(a) just below 0.5 $\mathrm{V}$, and hence very close to the position of the "Ni" peak of the "100-acid" NPs. More anodic, both "1-alkaline" samples showed a broad shoulder near the potential where the "100-acid" sample showed its most intense current density peak associated with CO stripping [marked "Pt" in Fig. 13(a)]. This suggests that Ni, Ni hydroxide species and maybe defects in or near the surface are responsible for the early $\mathrm{CO}$ oxidation onset.

Both, the octahedral and spherical $\mathrm{PtNi} / \mathrm{C}$ "20-alkaline" samples exhibited a very similar CO oxidation voltammogram as compared to their "1-alkaline" sample. In light of the XPS results of Fig. 11, the "20-alkaline" CVs appear fairly insensitive to moderate changes in the surface $\mathrm{Ni} / \mathrm{Pt}$ ratio (lower for the s-PtNi/C sample) or the metal oxidation state (higher content of cationic Pt species for oct-PtNi/C).

Table 1 provides a synopsis of the electrochemically active surface areas (COECSA) evaluated from the various voltammetric stripping curves. The Pt/C NPs showed consistent ECSA values, in good agreement with earlier reports. ${ }^{56,58,72,73}$ The ratio of CO-based ECSA and $\mathrm{H}_{\text {upd }}$-based ECSA for Pt/C was 1.08, confirming consistency between the two surface area evaluation methods. CO-ECSA values of the $\mathrm{PtNi} / \mathrm{C}$ NPs were also comparable between the acid and alkaline measurements (see Table 1). The somewhat larger oct-PtNi/C NPs showed higher ECSA values than the smaller spherical NPs, contrary to intuition. The reason for this could lie in the surface roughness of the concave octahedral NPs offering an increased number of $\mathrm{CO}$ adsorption sites. Furthermore, CO-ECSA values of the "1-alkaline" and "20-alkaline" samples were consistent, suggesting a negligible reduction in $\mathrm{CO}$ adsorption during prolonged potential cycling. It is noteworthy that the ratio of COECSA and $\mathrm{H}_{\text {upd }}$-ECSA was about 1.5 for both the spherical and the octahedral "100-acid" NPs. This area ratio has been linked to weakened hydrogen surface binding as compared to standard Pt. A value of the ratio larger than one has recently even been considered diagnostic for the formation of a Pt alloy skin surface, consisting of a single segregated $\mathrm{Pt}$ monolayer with the second layer being non-noble metal enriched. Unfortunately, due to the inelastic mean free path of electrons or XPS probe-depth, the XPS results cannot provide unambiguous evidence for the formation of a skin surface structure. The observed voltammetric charge ratio value of 1.5 means that the Pt skin-like hydrogen adsorption properties ${ }^{70}$ can also appear in aciddealloyed core-shell surfaces when treated in alkaline electrolytes, even in the absence of any thermal pretreatment. It is conceivable that the $\mathrm{CO}$ catalysis in
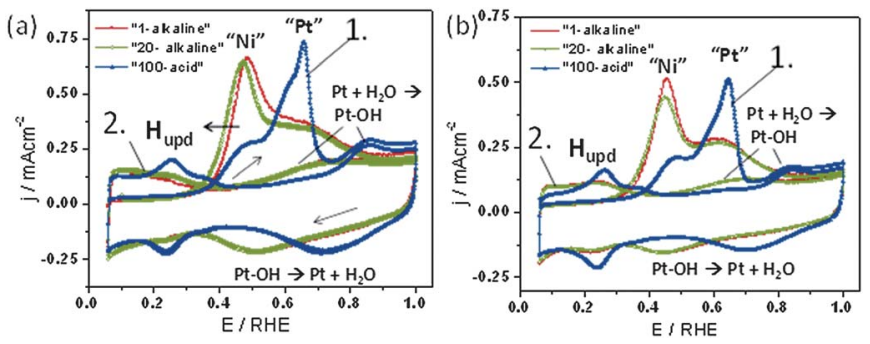

Fig. 13 First and second $\mathrm{CO}$ electrooxidation voltammograms of (a) oct-PtNi/C and (b) s-PtNi/C catalysts in alkaline solutions ( $\mathrm{pH} 13)$ after different pretreatments. Arrows indicate scan directions, scan numbers are marked. $\mathrm{H}_{\text {upd }}$ denotes voltammetric features associated with underpotential deposition and stripping of atomic hydrogen. Voltammetric peaks associated with the formation and reduction of $\mathrm{Pt}-\mathrm{OH}$ are indicated. 
Table 1 CO stripping-based electrochemically active surface areas (CO-ECSA) performed in alkaline and acid environments

\begin{tabular}{llll}
\hline Catalyst pretreatment & Catalyst & CO-ECSA (alkaline) $\mathrm{m}^{2} \mathrm{~g}^{-1} \mathrm{Pt}$ & CO-ECSA (acid) $\mathrm{m}^{2} \mathrm{~g}^{-1} \mathrm{Pt}$ \\
\hline \multirow{3}{*}{ "1-alkaline" } & $\mathrm{Pt}$ & 85 & $84.6^{a}$ \\
& s-PtNi & 53 & $\mathrm{~N} / \mathrm{A}$ \\
"20-alkaline" & oct-PtNi & 61 & $\mathrm{~N} / \mathrm{A}$ \\
& s-PtNi & 50 & $\mathrm{~N} / \mathrm{A}$ \\
"100-acid" & oct-PtNi & 60 & $\mathrm{~N} / \mathrm{A}$ \\
& s-PtNi & 37 & $38^{a}$ \\
\multirow{2}{*}{ CO-ECSA/H upd $^{-E C S A}$ ratios at $\mathrm{pH} 1: \mathrm{Pt} / \mathrm{C}: 1.08 ;$ s-PtNi/C $: 1.53 ;$ oct-PtNi/C $: 1.50}$. \\
\hline
\end{tabular}

alkaline electrolytes of the " 100 -acid" sample smoothed the surface by "electrochemical CO annealing" leading to the healing of surface defects, ${ }^{24}$ while aiding Ni to segregate toward the surface and thus created a near-surface alloy closely resembling a skin structure. The latter hypothesis is supported by the fact that the $\mathrm{CO}$ stripping voltammograms of "100-acid" oct-PtNi/C and s-PtNi/C NPs closely resemble that of a skin-type $\mathrm{PtNi}^{70}$

Overall, the $\mathrm{CO}$ electrooxidation study demonstrates how a simple variation in the pretreatment environment can drastically alter the catalytic behavior of alloy electrocatalysts through environment-induced segregation and the presence of distinct active species in or near the catalyst surface.

Hydrogen evolution in alkaline conditions. In addition to the electrocatalytic $\mathrm{CO}$ oxidation reaction, we chose the electrocatalytic reduction of water to molecular hydrogen (hydrogen evolution reaction, HER) in an alkaline electrolyte as a model reaction to test the impact of acid and alkaline surface pretreatments. This reaction is of great importance for neutral and alkaline water splitting for chemical energy storage applications. While alkaline water electrolysis is generally preferred based on catalyst cost, an efficient HER catalysts for alkaline media is missing. Pt is the best known HER electrocatalyst in acidic conditions. However, it displays severe overpotentials (efficiency losses) in alkaline solutions. Fig. 14(a) presents the cyclic voltammetric behavior of the "1-alkaline" pretreated $\mathrm{Pt} / \mathrm{C}$, oct-PtNi/C, and $\mathrm{s}-\mathrm{PtNi} / \mathrm{C}$ catalysts in an alkaline electrolyte over a wide potential range from 0.05 to $1.0 \mathrm{~V}$ in order to show the $\mathrm{H}_{\text {upd }}$ as well as the water activation/PtOH formation regions. The pure Pt NPs show sharper $\mathrm{H}_{\text {upd }}$ as well as $\mathrm{PtOH}$ features $(0.3 \mathrm{~V}$ and $0.8 \mathrm{~V}$ ), while the alloy NPs exhibit much broader potential waves in either region. In agreement with earlier studies on $\mathrm{PtNi},{ }^{74}$ the alloy NPs exhibit a reduced $\mathrm{H}_{\text {upd }}$ charge due to the reduced interaction of atomic hydrogen with Ni-containing surface and subsurface layers. The onset of water activation occurs fairly early, namely at around $+0.5 \mathrm{~V}$ for both catalysts. No obvious difference can be detected between the spherical and the octahedral NPs. Fig. 14(b) presents the hydrogen evolution reactivity in the alkaline electrolyte (blue, green, red) of $\mathrm{Pt} / \mathrm{C}$ after the acid and alkaline pretreatments, and compares those with the activity of the hydrogen evolution on Pt in acidic electrolytes. The cathodic shift of the alkaline HER curves evidences that $\mathrm{Pt}$ is a much better electrocatalyst in acid than in alkaline solutions. The HER reactivity of $\mathrm{Pt}$ in alkaline solutions appears largely independent of the surface pretreatment, Fig. 14(b). In contrast to $\mathrm{Pt}, \mathrm{PtNi} / \mathrm{C}$ NPs showed a significantly improved HER behavior, approaching that of pure $\mathrm{Pt}$ in acidic conditions. We assume that the presence of Ni in the NPs is responsible for the general increase in the HER activity of the alloys. The pretreatments were found to induce noticeable differences in the HER activity. The " 100 -acid"-pretreated sample catalyzes the HER less efficiently as compared to the " 20 -alkaline" sample. The redistribution 

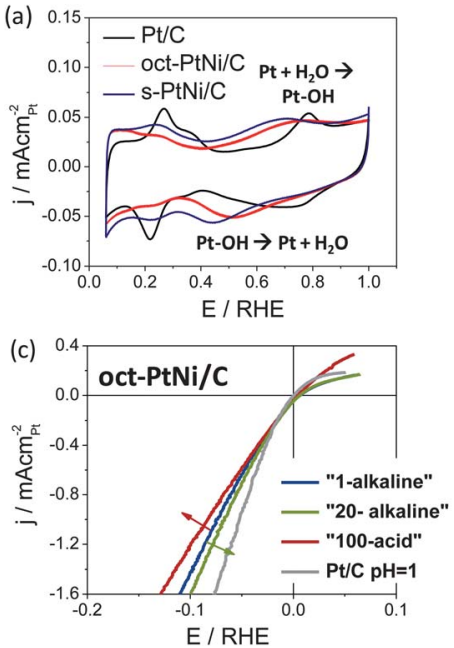
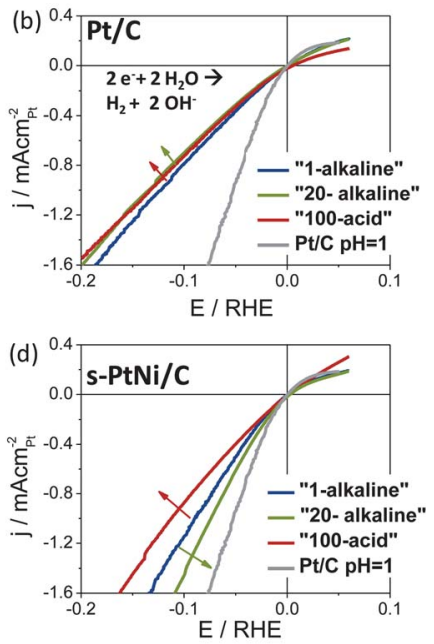

Fig. 14 (a) Cyclic voltammetry of spherical $\mathrm{Pt} / \mathrm{C}$, oct-PtNi/C, and s-PtNi/C NPs in $0.1 \mathrm{M}$ $\mathrm{KOH}$, (b)-(d) electrocatalytic HER activity in an alkaline 0.1 M KOH electrolyte (pH 13) of (b) $\mathrm{Pt} / \mathrm{C}$, (c) oct-PtNi/C, and (d) s-PtNi/C after pretreatments in alkaline and acid solutions.

of surface Pt and Ni hydroxide species coupled with the emergence of lower, more favorable surface $\mathrm{Ni} / \mathrm{Pt}$ ratios for HER could explain the additional activity gain of the "20-alkaline" catalyst. On the other hand, acid cycling associated with a strong depletion in Ni hydroxide on the NP surface could be responsible for the observed decrease in HER activity. As the data of spherical s-PtNi/C NPs in Fig. 14(d) illustrate, the influence of the NP shape on the catalytic HER activity is relatively small.

Bifunctional electrocatalysts through environment-induced segregation. The $\mathrm{CO}$ oxidation and HER catalysis served as model systems to demonstrate the drastic effect that pretreatments in electrochemical environments can have on surface structure and composition as well as on catalytic activity. Fig. 15 illustrates our hypotheses, based on the TEM, XPS and reactivity results, as to the surface chemical transformation during the electrochemical measurements. After synthesis, the (111) surfaces of oct-PtNi/C NPs consisted of a mix of Pt surface atoms and surface $\mathrm{Ni}(\mathrm{OH})_{2}$. After an initial alkaline pretreatment cycle ("1-alkaline") the surface formed a thick Ni hydroxide-rich layer, while the low electrode potentials reduced surface Pt oxides to metallic Pt. Ni was likely present in its $\alpha$-Ni hydroxide phase (green balls), which is the most stable Ni surface compound in the electrode potential range considered. ${ }^{75,76}$ Previous studies have shown that potential cycling can heal defects, and help remove low-coordinated adatoms analogous to thermal annealing in the gas phase. ${ }^{77}$ Along these lines, the present cycling in alkaline caused surface compositional changes and geometric rearrangements in the surface to attain the energetically most favorable state of the alloy surface. The existence of hydroxide anions in the electrolyte generally favors the presence of $\mathrm{Ni}$ oxides in the top layer, ["20-alkaline" in Fig. 15]. However, XPS also evidenced that potential cycling reduced the surface $\mathrm{Ni} / \mathrm{Pt}$ ratio. This could be due to either Pt surface segregation because of the Ni reduction, or to $\mathrm{Ni}$ inward diffusion and alloy formation in the $\mathrm{NP}$ core driven by the heat of alloying of $\mathrm{Pt}$ and $\mathrm{Ni}$.

Cycling pretreatment in acid environments selectively leached a significant portion of the surface Ni hydroxide species from the surface and subsurface region of the octahedral catalysts, ${ }^{66}$ resulting in an essentially Ni-free surface enclosing a subsurface PtNi alloy core (core-shell structural arrangement). When tested in acid 


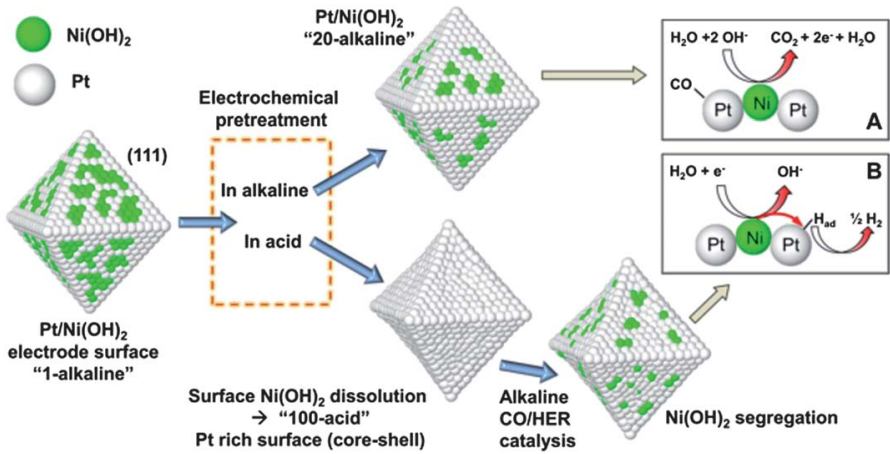

Fig. 15 Electrochemical surface dissolution/segregation processes in various electrochemical environments. $\mathrm{CO}$ oxidation and HER are enhanced due to bifunctional effects at $\mathrm{Pt}$ atoms adjacent to oxophilic $\mathrm{Ni}(\mathrm{OH})_{x}$ islands.

conditions, the subsurface Ni of the acid-leached PtNi NPs caused only a slight CO oxidation activity enhancement as evidenced by the $130 \mathrm{mV}$ shift of the major oxidation peak. When tested in alkaline solutions, however, ("alkaline CO/HER electrolysis" in Fig. 15) the hydroxide anions appeared to have caused a partial re-segregation of $\mathrm{Ni}$ species to the surface, evidenced by the emergence of the Ni-related CO oxidation peak around $0.5 \mathrm{~V}$ (marked "Ni"). The renewed presence of Ni surface species in the alkaline tested "100-acid" NPs was responsible for the activity enhancement in HER relative to pure Pt NPs.

Owing to their Ni hydroxide-rich surface, the alkaline-pretreated NPs showed a drastically increased $\mathrm{CO}$ oxidation activity around $0.5 \mathrm{~V}$ and displayed a catalytic HER activity approaching that of pure $\mathrm{Pt}$ in acidic conditions. Interestingly, the effect of the NP shape on surface chemistry and electrocatalysis was smaller than anticipated, and appeared negligible as compared to the drastic compositional segregation effects.

Mechanistically, the $\mathrm{CO}$ oxidation reaction proceeds via a Langmuir Hinshelwood reaction mechanism ${ }^{71}$ according to:

$$
\begin{gathered}
\mathrm{CO}+* \rightarrow \mathrm{CO}_{\mathrm{ad}} \\
\mathrm{OH}^{-}+* \rightarrow \mathrm{OH}_{\mathrm{ad}}+\mathrm{e}^{-} \\
\mathrm{CO}_{\mathrm{ad}}+\mathrm{OH}_{\mathrm{ad}}+\mathrm{OH}^{-} \rightarrow \mathrm{CO}_{2}+\mathrm{H}_{2} \mathrm{O}+\mathrm{e}^{-}+2 *
\end{gathered}
$$

On CO-covered Pt and Pt alloy surfaces at potentials below $0.5 \mathrm{~V}$, the CO oxidation cannot proceed due to missing active oxygenated surface species, symbolized by $\mathrm{OH}_{\mathrm{ad}}$. Hence, the adsorption of hydroxide anions and the resulting supply of active surface oxygenates represents the rate limiting step for the overall reaction. Pt NPs show an onset of $\mathrm{OH}$ formation more positive than $0.6 \mathrm{~V}$ [see Fig. 12(a)]. In the presence of Ni hydroxide islands or clusters at the NP surface, the supply of activated water or hydroxide according to reaction eqn (2) commences earlier, resulting in the observed cathodic shift of the CO oxidation [peak "Ni" in Fig. 12(b,c) and 13(a,b)]. This notion is illustrated in inset A of Fig. 15, where Ni surface species are shown to serve as active site for water and anion activation.

The HER is probably the most intensely studied reaction in electrochemistry. ${ }^{78,79}$ Its mechanism in alkaline solution is treated as a combination of the Volmer reaction 
step (4) involving the dissociation of water to form a weakly adsorbed reactive $\mathrm{H}_{\mathrm{ad}}$ intermediate, followed by either the Tafel recombination (5) or the Heyrovsky step (6) according to:

$$
\begin{gathered}
2 \mathrm{H}_{2} \mathrm{O}+{ }^{*}+2 \mathrm{e}^{-} \rightarrow 2 \mathrm{H}_{\mathrm{ad}}+2 \mathrm{OH}^{-} \\
2 \mathrm{H}_{\mathrm{ad}} \rightarrow \mathrm{H}_{2}+2 * \\
\mathrm{H}_{\mathrm{ad}}+\mathrm{e}^{-}+\mathrm{H}_{2} \mathrm{O} \rightarrow \mathrm{H}_{2}+\mathrm{OH}^{-}+*
\end{gathered}
$$

The initial formation of the active adsorbed hydrogen (4) from a water molecule is generally considered a slow reaction step, making the activation of water a critical process to enhance the HER catalysis in alkaline solutions. The HER in acidic solutions, in contrast, involves the initial discharge of hydronium ions, which proceeds much faster associated with high HER activity. The oxophilicity and affinity to water adsorption of $\mathrm{Ni}$-hydroxides has been well established in the past. ${ }^{74,80-83}$ Based on that, we attribute the increased catalytic HER activity of the segregated PtNi alloy NPs, in particular, of the alkaline-pretreated NPs, to the improved water dissociation at Ni hydroxide patches (clusters) on the NP surface as compared to $\mathrm{Pt}$ surface atoms (see inset B in Fig. 15). Pt surface atoms adjacent to the Ni hydroxide accommodate the discharged reactive atomic hydrogen $\left(\mathrm{H}_{\mathrm{ad}}\right)$ and subsequently catalyze reactions (5) and/or (6). Combined, the $\mathrm{Pt} / \mathrm{Ni}(\mathrm{OH})_{2}$ system represents a bifunctional electrocatalyst with considerably enhanced HER activity. Furthermore, the study of the "100 acid" PtNi/C NPs demonstrated that efficient bifunctional Ni hydroxide cluster formation can originate from subsurface $\mathrm{Ni}$ species, and thus does not need to be carried out by deposition or coating of Ni clusters. ${ }^{74}$

\section{Conclusions}

Gas-phase chemical and liquid electrochemical environments can induce significant compositional and structural changes in solid alloy surfaces, especially those in the $\mathrm{nm}$-size regime. Chemical and electrochemical environments form distinctly different types of interfaces to solids. For example, due to the absence or presence of an electrified double layer and mobile ions, distinctly different molecular interactions with surfaces are possible. However, our study demonstrates that gas-solid and liquid-solid interfaces also display commonalities, indicating certain unifying basic physico-chemical concepts.

Under various gaseous environments, octahedral PtNi NPs showed Ni : Pt ratios $>1$ and followed the trend: $(\mathrm{Ni} / \mathrm{Pt})_{\mathrm{O}_{2}}>(\mathrm{Ni} / \mathrm{Pt})_{\text {Vacuum }}>(\mathrm{Ni} / \mathrm{Pt})_{\mathrm{H}_{2}}$. Furthermore, the latter trend directly correlates with the relative $\mathrm{Ni}(\mathrm{II})$ species in our samples. Interestingly, the initial presence of $\mathrm{NiOx}$ species on the as-prepared samples played a pivotal role in the atomic segregation observed before the onset temperature for drastic NiOx reduction (i.e., below $300{ }^{\circ} \mathrm{C}$ ). In particular, when a large content of $\mathrm{NiOx}$ species was present on the as-prepared samples, preferential Ni segregation to the NP surface was observed, even in reducing environments.

In analogy to the oxygen gas-phase pretreatments, electrochemical hydroxide anions stabilized thick Ni hydroxide-rich surfaces during the initial potential cycle. Subsequent cycles established a surface with more balanced $\mathrm{Pt}$ : Ni hydroxide ratios with novel synergetic properties. Acidic electrochemical environments caused the selective removal of surface $\mathrm{Ni}$ species, a reactive pathway generally less common in gas-phase environments. The alkaline pretreated catalyst NPs showed significantly increased $\mathrm{CO}$ electrooxidation and electrocatalytic hydrogen evolution 
activity for which the water activation ability of surface-segregated Ni hydroxides is held responsible. Coupled with the formation of suitable adjacent $\mathrm{Pt}$ surface atomic ensembles, the Ni hydroxide islands represents the self-organized formation of efficient bifunctional catalysts.

We expect that similar electrochemical segregation phenomena could occur in other Pt bimetallic alloy NPs or surface reactions, especially where surface active electrolytes or reactants are involved. As an example, during the electrocatalytic reduction of molecular oxygen, the catalyst surface may transform under operando conditions and change its catalytic properties due to emerging synergistic bi- or multifunctionalities.

\section{Acknowledgements}

The work at TUB was supported by the U.S. Department of Energy, DOE-EERE award DE-EE0000458 via subcontract through General Motors. P.S. acknowledges support from the cluster of excellence in catalysis (UniCat). The work at UCF was funded by the U.S. National Science Foundation (NSF CHE-1213182).

\section{References}

1 D. L. Fedlheim and C. A. Foss, Metal Nanoparticles: Synthesis Characterization \& Applications, CRC - Taylor Francis Group, London, 2001.

2 G. Schmid, Nanoparticles: From Theory to Applications, Wiley-VCH, New York, 2004.

3 D. Astruc, Nanoparticles and Catalysis, Wiley-VCH, New York, 2007.

4 M. Oezaslan, M. Heggen and P. Strasser, J. Am. Chem. Soc., 2012, 134, 514-524.

5 B. Coq and F. Figueras, Coord. Chem. Rev., 1998, 178-180, 1753-1783.

6 G. C. Bond, Surf. Sci., 1985, 156, 966-981.

7 M. Arai, J. Chem. Eng. Jpn., 1997, 30, 1123-1125.

8 H. Gentsch, N. Guillen, V. Hartel and M. Kopp, Ber. Bunsen-Ges. Phys. Chem, 1973, 77, 1023-1023.

9 S. Mukerjee, J. Appl. Electrochem., 1990, 20, 537-548.

10 S. Eppell, G. S. Chottiner and D. A. Scherson, Abstr. Pap. Am. Chem. S., 1989, 197, $103-$ COLL.

11 I. Lee, R. Morales, M. A. Albiter and F. Zaera, Proc. Natl. Acad. Sci. U. S. A., 2008, 105, 15241-15246.

12 S. Linic and P. Christopher, Chem CatChem, 2010, 2, 1061-1063.

13 S. Kundu and H. Liang, J. Colloid Interface Sci., 2011, 354, 597-606.

14 S. Mostafa, F. Behafarid, J. R. Croy, L. K. Ono, L. Li, J. C. Yang, A. I. Frenkel and B. Roldan Cuenya, J. Am. Chem. Soc., 2010, 132, 15714-15719.

15 B. Roldan Cuenya, A. I. Frenkel, S. Mostafa, F. Behafarid, J. R. Croy, L. K. Ono and Q. Wang, Phys. Rev. B: Condens. Matter Mater. Phys., 2010, 82, 155450.

16 L. K. Ono, D. Sudfeld and B. Roldan Cuenya, Surf. Sci., 2006, 600, 5041-5050.

17 M. T. M. Koper, Nanoscale, 2011, 3, 2054-2073.

18 C. Coutanceau, P. Urchaga, S. Brimaud and S. Baranton, Electrocatalysis, 2012, 3, $75-87$.

19 Q.-S. Chen, F. J. Vidal-Iglesias, J. Solla-Gullón, S.-G. Sun and J. M. Feliu, Chem. Sci., 2012, 3, 136.

20 K. An and G. A. Somorjai, ChemCatChem, 2012, 4, 1512-1524.

21 S. S. Cheong, J. D. Watt and R. D. Tilley, Nanoscale, 2010, 2, 2045-2053.

22 M. Chen, B. H. Wu, J. Yang and N. F. Zheng, Adv. Mater., 2012, 24, 862-879.

23 F. Tao, M. E. Grass, Y. Zhang, D. R. Butcher, J. R. Renzas, Z. Liu, J. Y. Chung, B. S. Mun, M. Salmeron and G. Somorjai, Science, 2008, 322, 932-934.

24 K. J. J. Mayrhofer, V. Juhart, K. Hartl, M. Hanzlik and M. Arenz, Angew. Chem., Int. Ed., 2009, 48, 3529-3531.

25 K. J. Andersson, F. Calle-Vallejo, J. Rossmeisl and L. Chorkendorff, J. Am. Chem. Soc., 2009, 131, 2404-2407.

26 J. Nerlov and I. Chorkendorff, Catal. Lett., 1998, 54, 171-176.

27 J. Nerlov and I. Chorkendorff, J. Catal., 1999, 181, 271-279.

28 R. T. Mu, Q. A. Fu, H. Xu, H. I. Zhang, Y. Y. Huang, Z. Jiang, S. O. Zhang, D. L. Tan and X. H. Bao, J. Am. Chem. Soc., 2011, 133, 1978-1986.

29 R. T. Mu, X. G. Guo, Q. Fu and X. H. Bao, J. Phys. Chem. C, 2011, 115, 20590-20595.

30 K. Liu, A. Q. Wang and T. Zhang, ACS Catal., 2012, 2, 1165-1178. 
31 D. Wang, H. L. Xin, R. Hovden, H. Wang, Y. Yu, D. A. Muller, F. J. DiSalvo and H. D. Abruña, Nature Mater., 2012.

32 B. N. Wanjala, J. Luo, R. Loukrakpam, B. Fang, D. Mott, P. N. Njoki, M. Engelhard, H. R. Naslund, J. K. Wu, L. Wang, O. Malis and C.-J. Zhong, Chem. Mater., 2010, 22, 4282-4294.

33 S. Alayoglu, A. U. Nilekar, M. Mavrikakis and B. Eichhorn, Nat. Mater., 2008, 7, 333-338.

34 F. Tao, M. E. Grass, Y. Zhang, D. R. Butcher, J. R. Renzas, Z. Liu, J. Y. Chung, B. S. Mun, M. Salmeron and G. A. Somorjai, Science, 2008, 322, 932-934.

35 Y. Ma and P. B. Balbuena, Surf. Sci., 2008, 602, 107-113.

36 G. F. Wang, M. A. Van Hove, P. N. Ross and M. I. Baskes, Prog. Surf. Sci., 2005, 79, 2845.

37 V. Stamenković, T. J. Schmidt, P. N. Ross and N. M. Marković, J. Electroanal. Chem., 2003, 554-555, 191-199.

38 S. Deckers, F. Habraken, W. van der Weg, A. Denier van der Gon, B. Pluis, J. van der Veen and R. Baudoing, Phys. Rev. B, 1990, 42, 3253-3259.

39 J. Eymery and J. C. Joud, Surf. Sci., 1990, 231, 419-426.

40 R. Najafabadi and D. J. Srolovitz, Surf. Sci., 1993, 286, 104-115.

41 A. V. Ruban, H. L. Skriver and J. K. Norskov, Phys. Rev. B, 1999, 59, 15990-16000.

42 G. Wang, M. A. Van Hove, P. N. Ross and M. I. Baskes, J. Chem. Phys., 2005, 122, 024706.

43 A. U. Nilekar, A. V. Ruban and M. Mavrikakis, Surf. Sci., 2009, 603, 91-96.

44 C. W. Su, H. Y. Ho, C. S. Shern and R. H. Chen, Surf. Sci., 2002, 499, 103-108.

45 R. Mu, Q. Fu, H. Liu, D. Tan, R. Zhai and X. Bao, Appl. Surf. Sci., 2009, 255, 7296-7301.

46 T. Jacob, B. V. Merinov and W. A. Goddard, Chem. Phys. Lett., 2004, 385, $374-377$.

47 C. A. Menning and J. G. Chen, J. Power Sources, 2010, 195, 3140-3144.

48 Y. Ma and P. B. Balbuena, Surf. Sci., 2009, 603, 349-353.

49 J. R. Kitchin, J. K. Nørskov, M. A. Barteau and J. G. Chen, J. Chem. Phys., 2004, 120, 10240 .

50 V. R. Stamenkovic, B. Fowler, B. S. Mun, G. Wang, P. N. Ross, C. A. Lucas and N. M. Markovic, Science, 2007, 315, 493-497.

51 Y. Wu, S. Cai, D. Wang, W. He and Y. Li, J. Am. Chem. Soc., 2012, 134, 8975-8981.

52 P. Strasser, Rev. Chem. Eng., 2009, 25, 255-295.

53 F. R. Boer, R. Boom, W. Mattens, A. Miedema and A. Niessen, Cohesion in metals: transition metal alloys, Vol. 1, Elsevier Science Publishers B.V, 1988.

54 V. Stamenković, T. J. Schmidt, P. N. Ross and N. M. Marković, J. Phys. Chem. B, 2002, 106, 11970-11979.

55 F. Hasche, M. Oezaslan and P. Strasser, J. Electrochem. Soc., 2012, 159, B25-B34.

56 F. Hasche, M. Oezaslan and P. Strasser, ChemPhysChem, 2012, 13, 828-834.

57 M. Oezaslan, F. Hasché and P. Strasser, Chem. Mater., 2011, 23, 2159-2165.

58 F. Hasché, M. Oezaslan and P. Strasser, ChemCatChem, 2011, 3, 1805-1813.

59 R. Alessio, D. B. Dell Amico, F. Calderazzo, U. Englert, A. Guarini, L. Labella and P. Strasser, Helv. Chim. Acta, 1998, 81, 219-230.

60 Z. Liu, C. Yu, I. Rusakova, D. Huang and P. Strasser, Top. Catal., 2008, 49, 241-250.

$61 \mathrm{http}: / /$ www.casaxps.com.

62 S. G. Kwon and T. Hyeon, Small, 2011, 7, 2685-2702.

63 M. K. Carpenter, T. E. Moylan, R. S. Kukreja, M. H. Atwan and M. M. Tessema, J. Am. Chem. Soc., 2012, 134, 8535-8542.

64 C. Cui, L. Gan, H.-H. Li, S.-H. Yu, M. Heggen and P. Strasser, Nano Lett., 2012, 12, 58855889 .

65 S. H. Sun, C. B. Murray, D. Weller, L. Folks and A. Moser, Science, 2000, 287, 1989-1992.

66 L. Gan, M. Heggen, S. Rudi and P. Strasser, Nano Lett., 2012, 12, 5423-5430.

67 L. K. Ono, J. R. Croy, H. Heinrich and B. Roldan Cuenya, J. Phys. Chem. C, 2011, 115, $16856-16866$.

68 A. P. Grosvenor, M. C. Biesinger, R. S. Smart and N. S. McIntyre, Surf. Sci., 2006, 600, 1771-1779.

69 M. C. Biesinger, B. P. Payne, L. W. M. Lau, A. Gerson and R. S. C. Smart, Surf. Interface Anal., 2009, 41, 324-332.

70 D. F. van der Vliet, C. Wang, D. G. Li, A. P. Paulikas, J. Greeley, R. B. Rankin, D. Strmenik, D. Tripkovic, N. M. Markovic and V. R. Stamenkovic, Angew. Chem., Int. Ed., 2012, 51, 3139-3142.

71 M. Arenz, K. J. J. Mayrhofer, V. Stamenkovic, B. B. Blizanac, T. Tomoyuki, P. N. Ross and N. M. Markovic, J. Am. Chem. Soc., 2005, 127, 6819-6829.

72 S. Rudi, X. Tuaev and P. Strasser, Electrocatal., 2012, 1-9.

73 F. Hasche, M. Oezaslan and P. Strasser, Phys. Chem. Chem. Phys., 2010, 12, 15251-15258.

74 R. Subbaraman, D. Tripkovic, D. Strmcnik, K. C. Chang, M. Uchimura, A. P. Paulikas, V. Stamenkovic and N. M. Stamenkovic, Science, 2011, 334, 1256-1260. 
75 M. Jayalakshmi, M. M. Rao and K. B. Kim, Int. J. Electrochem. Sci., 2006, 1, 324-333.

76 M. P. Zach and R. M. Penner, Adv. Mater., 2000, 12, 878-883.

77 D. S. Strmcnik, D. V. Tripkovic, D. van der Vliet, K. C. Chang, V. Komanicky, H. You, G. Karapetrov, J. Greeley, V. R. Stamenkovic and N. M. Markovic, J. Am. Chem. Soc., 2008, 130, 15332-15339.

78 H. Gerischer, Z. Phys. Chem., 1956, 8, 137-153.

79 B. E. Conway and J. O. M. Bockris, J. Chem. Phys., 1957, 26, 532-541.

80 Q. Han, K. R. Liu, J. S. Chen and X. J. Wei, Int. J. Hydrogen Energy, 2003, 28, 1345-1352.

81 Q. Han, K. R. Liu, J. S. Chen and X. J. Wei, Int. J. Hydrogen Energy, 2003, 28, 1207-1212.

82 J. Greeley, L. Kibler, A. M. El-Aziz, D. M. Kolb and J. K. Nørskov, ChemPhysChem, 2006, 7, 1032-1035.

83 L. Birry and A. Lasia, J. Appl. Electrochem., 2004, 34, 735-749. 